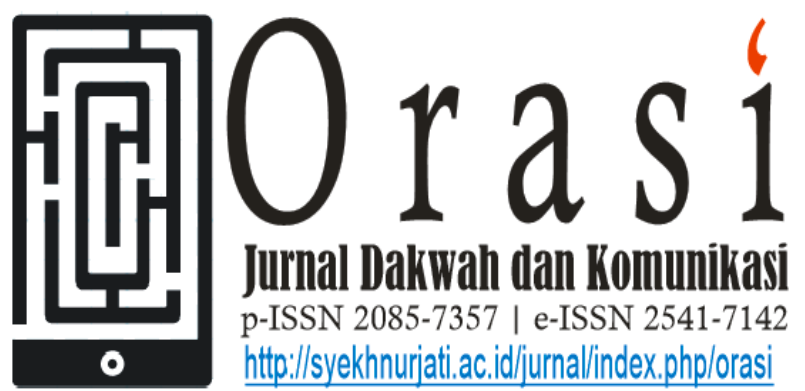

Volume 9 No. 2, PP 85 - 96; November 2018

\title{
EKSISTENSI RADIO REPUBLIK INDONESIA KENDARI PADA ZAMAN NOW
}

\author{
Abdul Jalil \\ Dosen Antropologi \\ FIB Universitas Halu Oleo Kendari Sulawesi Tenggara \\ abduljalil.uho@gmail.com
}

\begin{abstract}
ABSTRAK
Radio Republik Indonesia or RRI along with the development of globalization is required to be more creative, especially in greeting fans. Generation No w certainly harder to contribute unless introduced early on, in addition to the media for now more accessible, would need an innovation in order to remain one of the media that can entertain and provide information. The author has since been involved as one of the broadcasters of Rentak Pelangi Bumi Anoa (RPBA) Javanese language in 2017 to see that all this time (before 2018), RRI Kendari is still $C$ type with RPBA program only able to accommodate most of ethnic living in Anoa earth, Makassar, Bugis, Bajo, Tolaki, Buton, Muna, Moronene, Sunda, and Java, while some other ethnic groups have not been involved due to space constraints, such as Toraja and Bali, but since early 2018 has changed to type B. With type change, RPBA is no longer used, but merged into program 4 that is art and culture. This paper aims to reveal the need for the use of regional languages for the present generation to continue to love and uphold the noble values of Muna culture in particular, and generally on the audience to understand the culture of each region. In addition, this paper is the result of multicultural practice practice on RRI Kendari, with focus on Muna language RPBA. The method used is descriptive analytics that describe broadcast RPBA Muna language from the opening segment to greet with fans RRI Muna language, after it was analyzed. The results of this paper show that the overall contents of the song or hello poet with fans was more because the network, utamanay when the choice of the song is still not in the cluster.
\end{abstract}

Kata kunci: Eksistensi, RRI Kendari, Multikulturalisne, Bahasa Muna 


\section{PENDAHULUAN}

Terminologi "Eksistensi" sengaja penulis pilih untuk menunjukkan bahwa di era digitalisasi, era Now banyak masyarakat mendapatkan informasi yang dikehendaki, bahkan dari bangun tidur, kegiatan yang paling utama adalah membuka hand phone, membuka whats up, facebook, melihat berita serta informasi-informasi lain yang dibutuhkan sangat mudah untuk diakses tergantung paket data yang dimilikinya. Artinya media yang bernama Radio tentu semakin berat tantangannya, karena masingmasing masyarakat memiliki kecenderungan visual dari pada hanya sekedar mendengarkan. Meskipun demikian, Radio atau RRI yang nota bene milik pemerintah, tentu dalam memberikan informasi, hiburan, promosi dan edukasi dibutuhkan kiat-kiat tersendiri agar tetap menjadi selera masyarakat. Salah satunya adalah memaksimalkan sinergitas kerjasama dengan etnis-etnis yang ada di wilayah radio tersebut mengudara. Melalui program Rentak Pelangi Bumi Anoa/RPBA, RRI Kendari menjadi tetap ada di hati masyarakat, paling tidak dengan sesama etnis atau pecinta bahasa daerahnya.

Radio Republik Indonesia (RRI) merupakan lembaga penyiaran publik milik pemerintah, selain ada unsur edukasi bagi masyarakat, juga ada unsur hiburan dan promosi. Secara umum, program LPP RRI Kendari memberikan hiburan, pendidikan, informasi, dan kontrol publik. Empat program tersebut, bisa dikemas dalam bentuk acara dan program yang diselenggarakan dan bermakna atau mengandung keempatnya atau sebagian saja, bahkan hanya mengandung salah satu saja dari keempatnya (Abdul Jalil, 2016: 2). Acara Rentak Pelangi Bumi Anoa (RPBA) adalah sebuah acara yang berisi informasi terkait etnis dengan menggunakan bahasa tertentu, sehingga antara penggemar dan penyiar bisa saling sapa, sekaligus bisa dimaknai sebagai unsur hiburan karena setiap proses telepoon, selalu diawali dengan permintaan sebuah lagu sesuai dengan yang diinginkan pendengar atau pemerhati, terakhir dalam proses pemilihan lagu telah dikluster sesuai Daftar Acara Harian. Program RPBA dengan durasi waktu antara 1 sampai 1,5 jam, hanya ada jeda atau iklan sebanyak 4 kali. Tentu tidak semua penggemar bisa selalu menelepon berulang-ulang, selain tetap berbagi dengan penggemar yang lain, juga terkadang jaringan saluran telepon yang kurang bagus.

RRI adalah stasiun radio yang bertujuan untuk kepentingan bangsa dan 
Negara. Selain itu, RRI sebagai lembaga penyiaran publik bersifat independen, netral dan tidak komersial, serta berfungsi memberikan pelayanan siaran, informasi, pendidikan, hiburan dan kontrol yang sehat, serta menjaga citra positif bangsa di dunia Internasional. Adapun RRI Kendari adalah stasiun radio yang memiliki tiga program acara yaitu Pro 1 (program 1) dengan frekuensi 96,7 FM; kemudian Pro 2 (program 2) dengan frekuensi 90,8 FM dan yang terakhir adalah Pro 3 (Program 3) dengan frekuensi 91,6 FM yang berisikan tentang jaringan berita nasional. Semenjak tahun 2018 menjadi 4 (empat) program, yakni dengan ditambahkannya program 4, yaitu Seni dan Budaya, termasuk didalamnya memasukkan program RPBA, yang sebelumnya pada pro 1 (satu). RPBA adalah siaran budaya dari Sembilan (9) etnis yang memberikan informasi edukasi tentang budaya, baik dalam bentuk sebuah berita hingga mengenai hiburan terkait dengan etnis yang ada di Sulawesi Tenggara, misalnya: Tolaki, Muna, Moronene, Buton, Bajo, Makassar, Bugis, Sunda, dan Jawa.

Tulisan berikut akan mengeksplorasi RPBA bahasa Muna, selain menarik, juga penggunaan bahasanya sangat unik, sehingga bagi penulis menarik untuk ditulis. Lebih lanjut, dalam tulisan ini akan diuraikan teknis RPBA bahasa Muna mulai dari pembukaan sampai penutup, baik oleh penyiar sendiri maupun dari para penelepon. Selain itu, tulisan ini merupakan hasil pendampingan praktek kuliah lapangan mata kuliah multikulturalisme di RRI Kendari pada program RPBA yang nanti akan diuraikan tersendiri dalam pembahasan.

\section{KAJIAN LITERATUR}

\section{Rentak Pelangi Bumi Anoa (RPBA)}

Term "rentak" secara umum dapat dipahami sebagai kumpulan alunan musik masyarakat tertentu, sementara Pelangi sebagai simbol warna warninya etnis yang hidup dan berkembang di bumi anoa. Bumi anoa tidak lain adalah bumi Kendari. Menurut kasi penyiaran RRI Kendari, makna atau epistemologi penggunaan kata Rentak Pelangi Bumi Anoa (RPBA) yang kemudian dijadikan sebagai siaran atau program RRI Kendari tidak lain adalah sebagai wadah berhimpunnya beberapa etnis yang hidup dan berkembang di bumi Kendari, berangkat dari itulah kemudian RRI Kendari mencoba melibatkan berbagai etnis untuk bekerjasama melalui pengisian acara RPBA dengan bahasa yang dimiliknya (Abdul Jalil, 2016: 4-5).

Beberapa etnis yang telah mengisi dan bekerjasama dengan RRI, misalnya etnis Mornene, Makassar, Buton, Muna, Bugis, Tolaki, Bajo, Sunda, dan Jawa. 
Masing-masing etnis, biasanya diberikan ruang dan waktu yang sama setelah dilakukan kesepakatan antara pengampu atau penyiar RPBA bahasa etnis tertentu dengan pihak RRI di bawah Kasi Penyiaran Radio. Ilustrasi yang bisa dipahami bahwa dalam ruang penyiaran telah tersedia 4 kursi dengan meja bundar dan seperangkat media untuk menerima dan menyapa penggemar Radio RRI Kendari.

\section{Forum Komunikasi Pemerhati (FKP) RRI Kendari}

Forum Komunikasi Pemerhati RRI didirikan pada tanggal 25 Agustus 2010 di Jakarta, dengan visi terwujudnya forum komunikasi pemerhati RRI, yang mendukung LPP RRI sebagai Radio berjaringan terluas, membangun karakter bangsa, berkelas dunia. Adapun misinya, mendukung program siaran RRI dalam mencerahkan, mencerdaskan, dan memberdayakan masyarakat; menghimpun aspirasi masyarakat pemerhati RRI; dan melestarikan dan mengembangkan seni, budaya bangsa, dan teknologi (AD/ART FKP RRI).

\section{METODE PENELITIAN}

Penelitian ini dilakukan di LPP RRI Kendari dengan fokus informan penyiar Rentak Pelangi Bumi Anoa bahasa Muna. Penelitian ini akan mengungkap pada kurun waktu siaran di bulan Oktober
2017, karena dengan metode ini agendaagenda serupa dapat diketahui secara utuh. Mulai dari bagaimana para penyiar mulai membuka acara RPBA dengan para penggemar dan pemerhati saling sapa, saling titip salam, sampai pada sebuah kata penutup di setiap akhir tayangan.

\section{HASIL PENELITIAN DAN PEMBAHASAN}

Dalam pembahasan ini, penulis idealnya menampilkan semua acara RPBA yang melibatkan 9 (sembilan) etnis. Namun secara umum, pola yang ada dari semua siaran RPBA tersebut adalah sama, misalnya sebelum salam pembuka, biasanya didahului lagu khas daerah. Terkadang sebelum lagu khas daerah, juga diputar lagu pemersatu gelombang, misalnya lagu yang menunjukkan simbol pemersatu acara yaitu Rentak Pelangi Bumi Anoa. Setelah memasuki waktu tayang, biasanya diputar lagu khas daerah. Setelah selesai, maka akan dibuka oleh penyiar. Dalam sajian data ini, penulis mencoba menyamakan bahasa yang digunakan, meskipun dalam kenyataanya, tetap menggunakan bahasa etnis sebagaimana jadwal siaran bahasa Sembilan etnis yang telah ditentukan.

Berikut adalah jadwal penyiaran RPBA secara keseluruhan: 


\begin{tabular}{|c|c|c|}
\hline Hari & $\begin{array}{c}\text { Waktu } \\
\text { (Pukul/jam) }\end{array}$ & Suku/Etnis \\
\hline Senin & $\begin{array}{c}\text { Pukul 12:30- } \\
14: 00 \text { WITA }\end{array}$ & MAKASSAR \\
\hline Selasa & $\begin{array}{c}\text { Pukul 12:30- } \\
14: 00 \text { WITA }\end{array}$ & BAJO \\
\hline Rabu & $\begin{array}{c}\text { Pukul 12:30- } \\
14: 00 \text { WITA }\end{array}$ & BUGIS \\
\hline Kamis & $\begin{array}{c}\text { Pukul 12:30- } \\
14: 00 \text { WITA }\end{array}$ & TOLAKI \\
\hline Jum'at & $\begin{array}{c}\text { Pukul 12:30- } \\
14: 00 \text { WITA }\end{array}$ & BUTON \\
\hline Sabtu & $\begin{array}{c}\text { Pukul 12:30- } \\
14: 00 \text { WITA }\end{array}$ & MUNA \\
\hline Minggu & $\begin{array}{c}\text { Pukul 12:30- } \\
14: 00 \text { WITA }\end{array}$ & MORONENE \\
& $14: 0$ \\
\hline
\end{tabular}

Sedangkan untuk dua etnisnya yang lain, yakni Bahasa Sunda dan Jawa sebagai berikut:

\begin{tabular}{|c|c|c|}
\hline Hari & $\begin{array}{c}\text { Waktu } \\
\text { (pukul/jam) }\end{array}$ & Suku \\
\hline Jum'at & $\begin{array}{c}\text { Pukul 20:20- } \\
\text { 22:00 WITA }\end{array}$ & SUNDA \\
\hline Sabtu & $\begin{array}{c}\text { Pukul 20:20- } \\
\text { 22:00 WITA }\end{array}$ & JAWA \\
& \multicolumn{2}{|c|}{} \\
\hline
\end{tabular}

Sebagaimana pekerjaan seorang antropolog, saya bersama mahasiswa dalam praktik lapangan telah melakukan tiga kegiatan yang tidak lain adalah melakukan observasi, wawancara, dan dokumentasi. Observasi ini telah dilakukan bersama-sama dengan kelompok lain, tepatnya pada tanggal 12 Oktober 2017 dengan diterima langsung oleh Kasi Penyiar dan Penanggung jawab pro1.

Beberapa hal penting terkait audinesi tersebut dapat dijabarkan bahwa RRI adalah merupakan lembaga penyiar publik milik pemerintah. Programnya memberikan hiburan, pendidikan, informasi, dan kontrol publik. Selain itu, RPBA sendiri merupakan program bidang pengembangan masyarakat, selain program-program lainnya. Fajar ilahi, Siaran TK, Pojok Radio, Oasis,

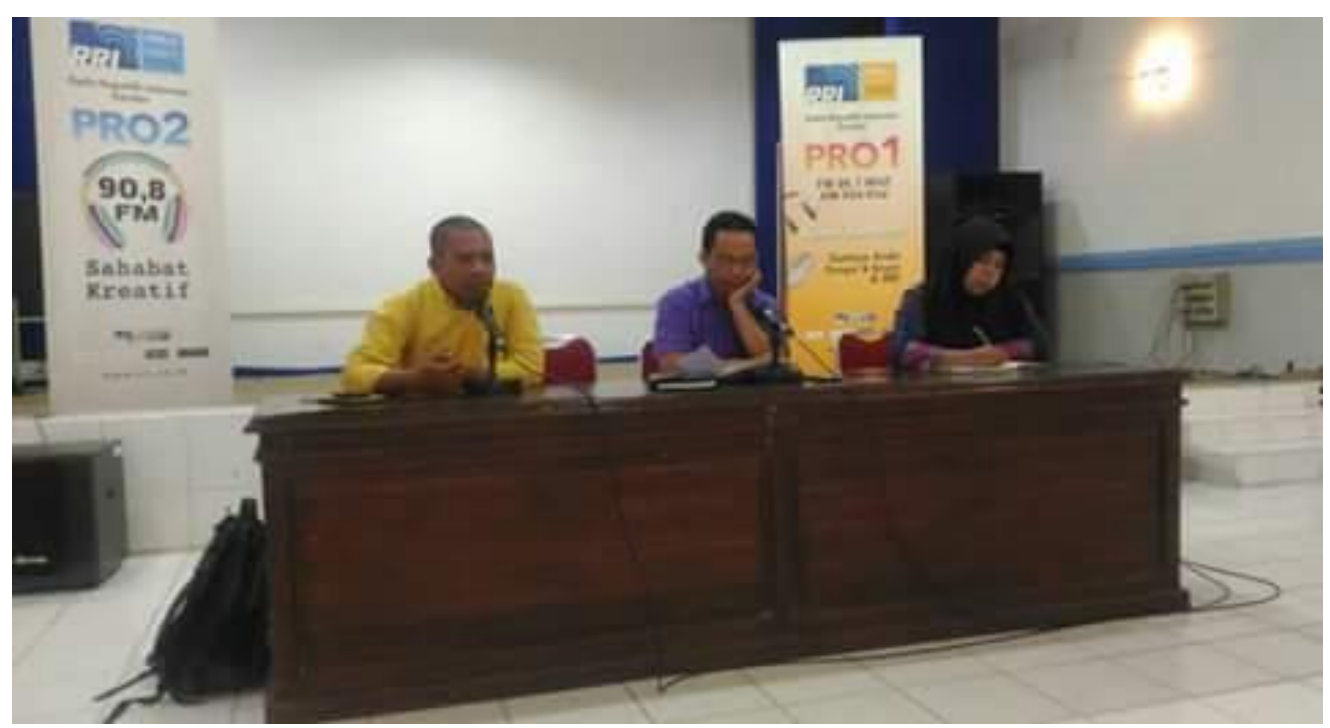

Gambar 1.1 audiensi oleh Kasi penyiar dan didampingi penanggung jawab pro1 yang diterima di aula RRI Kendari pada 12

Oktober 2017.

Dokument: Siti Sabariah. 
Renungan, Perempuan Indonesia, Mimbar Agama Islam, Katholik, Hindu, Budha, Protestan, Extrime, Anak cerdas Lokal, Derap Pramuka, Respek Your Life, Gita dan Sabda, Kramas fun English, English for Kids, dan Tafsir. Selain itu, yang perlu diungkap dalam hasil audiensi tersebut terkait dengan nilai-nilai multiklturalisme bahwa siaran RRI Kendari harus merefleksikan keberagaman, program siaran hendaknya berperspektif gender yang sesuai dengan budaya bangsa dan melayani kebutuhan kelompok-kelompok minoritas, dan terakhir prinsip LPP RRI merefleksikan keberagaman dan melayani pada khalayak (hasil audiensi dengan kasi RRI Kendari, Edi, 12 Oktober 2017).

Secara umum, bahasa siaran radio memiliki ragam tersendiri yang berbeda dengan ragam bahasa media massa lainnya. Untuk ragam bahasa siaran radio dalam segmen permintaan lagu (music request), berdasarkan variasi bahasa menurut Chaer dan Agustina (1995: 95) dapat diklasifikasikan ke dalam variasi bahasa dari segi keformalan yang termasuk ke dalam tiga ragam bahasa. Pertama, ragam resmi atau formal adalah variasi bahasa yang digunakan dalam pola dan kaidah resmi yang sudah ditetapkan secara mantap sebagai suatu standar; Kedua, ragam usaha yang wujudnya berada di antara ragam formal dan ragam informal atau ragam santai; Ketiga, ragam santai atau kasual radio dalam segmen acara permintaan lagu dapat diklasifikasikan ke dalam variasi bahasa menurut hubungan di antara pembicara yang membedakan ragam-ragam bahasa menurut akrab tidaknya pembicara. Penulis akan mencoba mendeskripsikan dan menganalisis bahasa siaran radio yang meliputi variasi bahasa pembuka dan penutup acara, panggilan nama diri penyiar dan sapaan kepada pendengar, jenis variasi yang digunakan, dan fungsifungsi kemasyarakatan dalam pemakaian bahasa yang digunakan penyiar

Pada hari Sabtu tanggal 14 Oktober 2017, anggota kelompok bahasa Muna melakukan sebuah wawancara mendalam di Radio Republik Indoenesia Kendari terkait dengan RPBA bahasa Muna. Acara dimulai dari pukul 12:3014:00 WITA dengan frekuensi 96,7 FM Pro 1. Adapun informan atau narasumber yang ada, sekaligus sebagai penyiar RPBA Muna adalah Bapak Amziah L Sambali yang lebih dikenal dengan nama udaranya Putra Mantobua berusia empat puluh delapan tahun (48 Tahun), berasal dari suku Muna, selain yang bersangkutan juga bekerja sebagai Asisten Manajer Sirkulasi di PT. Media Kita Sejahtera Kendari Pos. 
Berikut kutipan wawancara dengan Putra Mantobua.

"Pada awalnya nama RPBA ini adalah Goyang Gonta Ganti atau $3 \mathrm{G}$, namun pada tahun 2007, 3G ini diganti menjadi RPBA Karena 3G tidak mewakili dari semua suku atau etnis budaya di Sulawesi Tenggara sehingga diganti nama dari 3G menjadi RPBA"(wawancara dengan Putra Mantobua pada 14 April 2017).

Pergantian nama dari Goyang Gonta Ganti(3G) ini menjadi RPBA (Rentak Pelangi Bumi Anoa) dikarenakan Goyang Gonta Ganti tidak menggambarkan bahwa Sulawesi Tenggara adalah daerah yang Multikultural yang terdiri dari berbagai suku, baik suku asli (Tolaki) maupun suku pendatang dari luar Sulawesi Tenggara, termasuk Muna dan Buton. Dengan demikian, nama $3 \mathrm{G}$ ini tidak mewakili dari semua suku atau etnis yang ada di Sulawesi Tenggara, maka berganti menjadi RPBA (Rentak Pelangi Bumi Anoa).

Kata "Rentak Pelangi" menurut saya melambangkan warna-warninya suku atau keragamann suku, sementara kata "Bumi Anoa" melambangkan wilayah Sulawesi Tenggara. Berangkat dari sini, RPBA sangatlah cocok karena mewakili dan menggambarkan bahwa Sulawesi Tenggara adalah daerah yang multikultiral. Dalam siaran RPBA terdiri dari tiga segmen. Pertama, segmen pembukaan acara, dimulai pada saat acara dibuka yaitu pukul 12:30 WITA yang terdiri dari salam dari penyiar kepada para pendengar, kemudian segmen Kedua, terdiri dari pembacaan berita, serta segmen ketiga atau segmen terakhir yaitu terdiri dari sapa-sapa dan request lagu. Secara teknis, siaran RPBA bahasa Muna ini, mulai dari pembukaan sampai penutup tentu bahasa yang digunakan adalah bahasa Muna, baik oleh penyiar sendiri maupun dari para penelepon. Peraturan ini harus dipatuhi, karena jika tidak maka akan mengakibatkan hal yang fatal. Berikut kutipan wawancaranya:

“...ketika ada penelepon yang tidak menggunakan bahasa Muna pada saat proses penyiaran berlangsung, maka tidak bisa dilayani dengan mengungkapkan kata maaf kepada penelepon tersebut"(wawancara dengan Putra Mantobua, 14 Oktober 2017).

Pada segmen pertama atau pembukaan acara jika sudah selesai, maka dilanjutkan dengan segmen kedua yaitu pembacaan berita dengan menggunakan bahasa Muna. Untuk pembacaan berita ini, berita yang dibaca adalah berita yang berasal dari Tim pemberitaan dari RRI Kendari, bisa dari dua atau tiga hari sebelumnya atau bahkan bisa 1 hari sebelumnya, melihat penyiar secara tepat 
mampu mentranslate berita-berita berbahasa Indonesia ke dalam bahasa Muna, meskipun tidak berlaku untuk penyiar yang lain. Artinya kemampuan dan berani secara langsung mengalih bahasa dari bahasa Indoensia ke dalam bahasa Muna. Meskipun lebih banyak yang dilakukan oleh penyiar bahasa Muna tanpa mengalih bahasa ke bahasa daerah atau bahasa Muna. Artinya berita yang dibaca Putra Mantobua tetap menggunakan bahasa Indonesia. Sementara model pembacaan berita yang tidak jauh-jauh hari mengambilnya dari Tim pemberitaan untuk kemudian dialih bahasa ke dalam bahasa Muna akan mempersulit dirinya sendiri, atau dengan bahasa lain sangat beresiko besar bagi Putra Mantobua karena dapat mengakibatkan kesalahan fatal, terutama jika menemukan kata atau istilah dalam bahasa Indoensia yang tidak mudah ditemukan atau dimengerti dalam bahasa Muna.

Setelah pembacaan berita selesai, maka selanjutnya adalah sapa-sapa untuk para penelpon. Terdapat sistem interaktif antara penyiar dengan pemerhati, pendengar, atau penelpon yaitu terdiri dari penelepon pertama, kedua, ketiga dan seterusnya sampai waktu siaran berakhir. Untuk penelepon pertama, biasanya diminta oleh penyiar tanggapan terkait tema yang ada, kemudian bisa juga dihubungkan dengan informasi dari berita yang sesaat telah dibacakan. Meskipun demikian,tidak banyak yang mengomentari sebuah tema atau berita yang dibacakan oleh penyiar, pada umumnya hanya penyampaian salamsalam terhadap kolega, kemudian dilanjutkan request lagu karena sebagai penelpon pertama. Sebagai contoh, pada tanggal 14 Oktober tahun 2017, Putra Mantobua menyiarkan tentang "Tidak akan ada ijin untuk kendaraan kecil”, Dinas Perhubungan Kota Kendari tidak akan lagi mengeluarkan izin baru bagi angkutan kota untuk kendaraan kecil (Dinas Perhubungan we kota Kandari paem tora naefolimba izin bughou so angkutan karubuhi we kota). Ketika ada penelepon pertama, biasanya Putra Mantobua meminta kepada penelepon untuk sedikit mengomentari terkait dengan berita yang telah dibaca, namun penelopon biasanya hanya memilih untuk melakukan sapa-sapa dan request lagu tanpa memberikan komentar terkait tema atau berita yang dibacakan. Lebih detailnya, sebagaimana dalam isi berita sebagai berikut:

"Dinas perhubunganno kota kandari paem tora naefolimba izin bughou so angkutan karubuhi we kota. Dinas perhubunganno kota kandari, Muhammad Ali Aksah nobisara, datumanda aituini pamarintano kandari paem tora naefolimba izini so angkutan karubuhi tabeano so peremajaan kaawwu. 
Patudhuno Ali Aksah sapedano Patudhuno Ali Aksah sapedano wite momajuni bhe berkembangno, pamarintano kandari ampam kaawu naefolimba izino so trayek angkutan we kota naho nefonaando sebagianno unit kasawiha bhabhari bhe fasilitasi mopande, tapeda obus trans lulo, nealahi penumpa welo daerah kandari, mahingkam PNS, masyarakati biasa mahingkam tora mahasiswa bhe siswahi. Labhino tora Ali Aksah nobisaragho rencanano daehapusu kasawiha tapeda kasawiha karubuhi meoperasino welo kota kandari, dokira-kirae kabharino nolabhi ramoghono(200) bhe sebagiano rute numandoono".

Setelah penelepon pertama melakukan sapa-sapa/salam-salam dan request lagu, kemudian dilanjutkan dengan menerima penelpon kedua, ketiga, dan seterusnya sampai diperkirakan waktunya selesai. Bagi penelpon kedua, hanya bisa melakukan sapa-sapa/ salamsalam dan tidak bisa melakukan request lagu, hal ini juga berlaku bagi penelepon ketiga dan keempat sampai kemudian pemutaran lagu dari request penelepon pertama. Lagu yang direquest oleh para penelepon, biasanya sudah di list oleh staf RRI yang kemudian putra Mantobua memberi pilihan kepada para penelepon untuk memilih. Lagu lagu yang di list oleh staf RRI atau penanggung jawab pada daftar menu harian tentu berbedabeda setiap harinya. Hari Sabtu yang lalu (7 Oktober 2017), beberapa lagu yang direquest adalah: Kabua-Bua (anak remaja perempuan), Sura so Poraeku (surat untuk kekasihku), Palalei (mengusir), Mie Marasai (orang yang tidak mampu), dan Lampurege. Pada kata yang terakhir ini, saya belum bisa memberikan pengertian, barangkali itu warisan leluhur yang belum sempat ditransmisikan atau diwarsikan ke generasi sekarang. Sebagi ilustrasi, kata yang berubah adalah "sandal", kata ini dimaksudkan alas kaki, namun penyebutan generasi dahulu "kalapiti", namun genarsi sekarang dengan penambahan Sandali (wawancara Anshar, mahasiswa antropologi FIB UHO semester 8).

Pada saat pemutaran lagu selesai di putar, maka kembali lagi seperti sebelumnya yaitu penelepon pertama sapa, salam dan request lagu. Untuk lagu yang direquest, para penelepon biasanya merequest lagu sesuai dengan keadaan hati yang mereka alami atau diperuntukkan atau dipersembahkan untuk seseorang, artinya setiap yang mereka request lagu, pasti ada sebuah makna yang terkandung di dalamnya. Seperti penelpon pada tanggal 14 Oktober 2017 lalu, yang bernama Bapak Apoati merequest lagu Sura So Poraeku (surat untuk kekasih, bisa suami untuk istri atau sebaliknya), lagu ini mengisahkan seorang istri yang sedang berada di luar kota.

Pada segmen sapa-sapa, yang tidak lain adalah segmen reques lagu 
sendiri tidak dibatasi, selama waktu masih tersedia yakni sampai pukul 14:00 WITA. Biasanya terdiri dari beberapa fase yaitu, fase pertama terdiri dari 5 penelpon mengenai keberagaman budaya yang ada di Sulawesi Tenggara, salah satunya adalah Suku Muna. Dalam siaran RPBA terdiri dari tiga segmen. Pertama

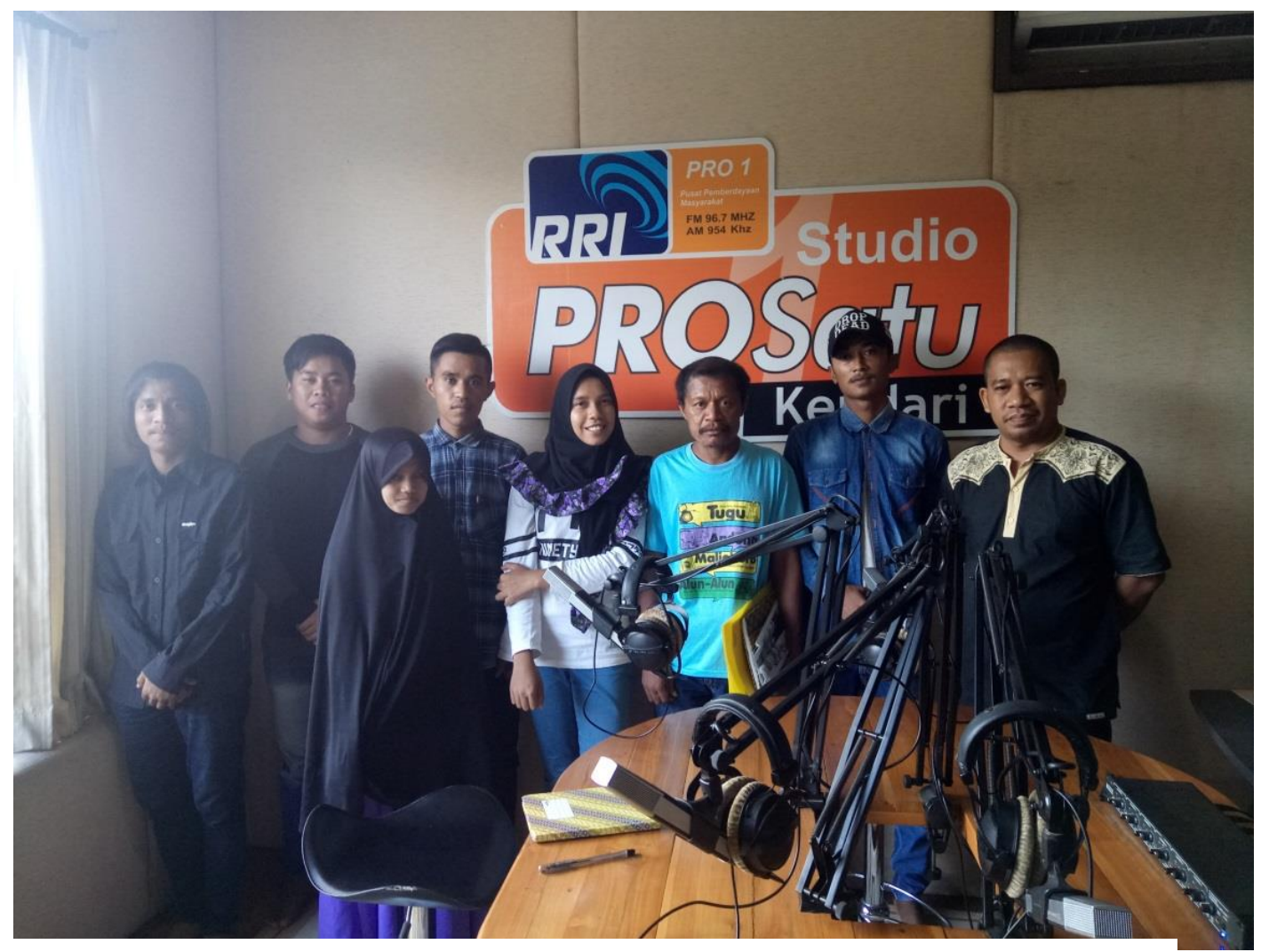

Gambar 1.2 Tim Kelompok Muna, Putra Montobua, dan Abdul Jalil (Dosen Pembimbing)

Sumber: RRI Kendari Pro 1 Jln. La Ute No. 44 Mandonga

Dokumentasi: Bapak Andre

sampai istrahat atau hiburan (pemutaran lagu), kemudian fase kedua terdiri dari 5 penelpon lagi dan seterusnya sampai pada penutup.

\section{PENUTUP}

\section{Kesimpulan}

Dari pembahasan tersebut, dapat ditarik kesimpulan bahwa RPBA adalah sebuah program dari PRO 1 stasiun RRI Kendari yang memberikan informasi pembukaan acara, dimulai pada saat acara dibuka yaitu pukul 12:30 WITA yang terdiri dari salam dari penyiar kepada para pendengar-pemerhati; Kedua, terdiri dari pembacaan berita; dan Ketiga atau segmen terakhir yaitu terdiri dari sapasapa dan request lagu dari pendengar kepada penyiar. Mulai dari pembukaan sampai penutup tentu bahasa yang digunakan adalah bahasa daerah yakni bahasa Muna, baik oleh penyiar sendiri 
maupun dari para penelpon. Peraturan ini harus dipatuhi, karena jika tidak, maka akan mengakibatkan hal yang fatal, yakni penyiar dapat memutus jaringan telpon secara sepihak.

$\begin{array}{rccc}\text { Selain itu, RRI } & \text { Kendari } & \text { selalu } \\ \text { berinovasi menjadi } & \text { bagian } & \text { dalam }\end{array}$ pembangunan anak bangsa melalui program-program yang lebih sesuai dengan kebutuhan atau selera masyarakat dengan tetap mengedepankan siaran berperspektif gender sesuai dengan budaya bangsa dan melayani kebutuhan kelompok-kelompok minoritas. RRI Kendari pada tahun 2018 ini, setelah meningkat menjadi tipe $B$, program RPBA dibawah pro 4 yang nota bene sebagai program bidang seni dan budaya dalam mata kprogram "sahabat budaya" bersamaan dengan beberapa etnis, termasuk Bali. Adapun nilai-nilai multikulturalisme RPBA bahasa Muna, saya maksudkan bahwa program-program RRI ini selalu melibatkan berbagai etnis yang ada di Sulawesi Tenggara, baik pada 2017 atau sebelumnya dengan program RPBA maupun pada tahun 2018 di pro 4 dengan program "Sahabat Budaya" yang tayang pada malam hari dengan frekuensi $10.34 \mathrm{fm}$ dari jam 21.00-22.30 WITA. Selain itu, request lagu yang telah dikluster atau ditentukan oleh penanggung jawab studio, baik pro1, pro2,dan pro4 khususnya dalam program RPBA atau "Sahabat Budaya" dapat digali daari makna di setiap lirik lagu yang direquest oleh pendengar/pemerhati. Hal ini, sebagai bentuk pentingnya pelestarian budaya luhur dengan tetap melestarikan penggunaan bahasa daerah, mengutamakan penggunaan bahasa Indonesia serta bahasa asing dikuasai sebagaimana dalam jargon bulan bahasa yang diperingati setiap September.

\section{Saran}

Terkadang siaran RRI Kendari belum punya bergaining posisi yang kuat, di satu sisi penyiaran publik, disisi lain penulis menangkap tetap adanya eveneven tertentu yang syarat dengan sponsor, biasanya agenda RPBA atau "Sahabat Budaya" sering dinomor duakan. Artinya RPBA atau nama lain dilaksanakan setelah kegiatan on air dalam even-even yang oleh pihak ketiga siap memberi jam acara yang sudah ada sebelumnya, selain itu penyiar RPBA oleh para orang-orang yang sudah ditunjuk juga tidak bisa melakukan apa-apa. Padahal, penggemar atau pemerhati yang sudah siap menyapa urung karena tidak ada pemberitahuan jauh-jauh hari. 
DAFTAR PUSTAKA

Multikulturalisme Dalam Perspektif

Antropologi, bahan ajar mata

kuliah multikulturalisme, 2015.

Anggaran Dasar Forum Komunikasi

Pemerhati RRI (FKP RRI), 2011.

UU Nomor 32 Tahun 2002 tentang Penyiaran

PP Nomor 11 Tahun 2005 tentang Penyelenggaraan LPP

PP Nomor 12 Tahun 2005 tentang LPP RRI

Kebijakan Umum LPP RRI 2010-2015

Pedoman Penyelenggaraan Siaran Program Satu Dan Dua, 2011

Peraturan Direktur Utama LPP RRI Nomor: 03 Tahun 2016 tentang perubahan penetapan jenis dan tarif atas jenis penerimaan negara bukan pajak yang diklasifikasikan dalam zona jaringan nasional dan zona $\mathrm{A}$, $\mathrm{B}$, dan $\mathrm{C}$ yang berlaku pada lembaga Penyiaran Publik Radio Republik Indonesia.

Jalil, Abdul. Mempromosikan Multikulturalisme Pada Program "Rentak Pelangi Bumi Anoa" Di Radio Republik Indonesia Kendari Sulawesi Tenggara. 2016. Prosiding dalam Simposium Internasional-Bahasa-bahasa

Lokal, Nasional, dan Global Kerjasama UHO dg APBL, 27-29
Oktober 2016 di Pasca UHO Kendari Sultra.

\section{Internet:}

http://rri.co.id/profil.html

lihat Peraturan Dirut LPP RRI No. 3 Tahun 2016

https://www.scribd.com/doc/236193962/P embukaan-Siaran-Radio.

Gowa”. ejournal.uin-alaudin.ac.id 